\title{
STUDI IDENTIFIKASI SPESIES KANTONG SEMAR (Nepenthes spp.) DI KAWASAN CAGAR ALAM LEMBAH HARAU KABUPATEN LIMA PULUH KOTA SUMATERA BARAT
}

\author{
Elmiwati
}

Dosen STKIP Abdi Pendidikan Payakumbuh

\begin{abstract}
ABSTRAK
Kantong semar (Nepenthes spp.) merupakan tumbuhan karnivora yang hidup didaerah tropis salah satunya di Cagar Alam Lembah Harau, tingginya tingkatan eksplorasi dan penjualan nepenthes sebagai tanaman hias diperkirakan dapat menurunkan jumlah spesies nepenthes, saat ini kantong semar (Nepenthes spp) termasuk kedalam CITES (Convension On International Trade Of Endangered Spesies) dalam Apendiks I dan II yang tergolong hampir punah dan langka.

Penelitian ini adalah penelitian deskriptif dengan menggunakan metode survey. Penelitian dilakukan pada mulai bulan Oktober - November 2014 di Kawasan Cagar Alam Lembah Harau Kabupaten Lima Puluh Kota Sumatera Barat. Teknik pengumpulan data dilakukan dengan observasi langsung dilapangan, serta mengidentifikasi spesies yang didapatkan di Laboratorium Biologi STKIP Abdi Pendidikan Payakumbuh.

Berdasarkan hasil penelitiandidapatkan 4 spesies kantong semar (Nepenthes spp ) yaitu Nepenthes Albomarginata, Nepenthes ampullaria Jack, Nepenthes eustachya Miq, Nepenthes gracilis Korth dikawasan Cagar Alam Lembah Harau. Spesies kantong semar yang ditemukan di lokasi penelitian pada umumnya tumbuh di tanah atau terrestrial dengan batang memanjat (scandes).
\end{abstract}

Kata kunci: kantong semar, cagar alam

\section{PENDAHULUAN}

Indonesia merupakan Negara kepulauan terbesar di dunia yang terdiri dari 17.504 pulau, tersebar dari Sabang hingga ke Merauke. Sejumlah besar (lebih dari 10.000 buah) dari jumlah pulau-pulau tersebut merupakan pulaupulau berukuran kecil yang memiliki keanekaragaman tumbuhan, hewan dan jasad renik yang tinggi (Irwanto, 2005:1).

Sebagian besar hutan Indonesia termasuk kedalam hutan hujan tropis basah yang mempunyai vegetasi hutan yang cukup heterogen dari berbagai jenis spesies dari tingkat rendah sampai tingkat tinggi. Ditegakan (vegetasi) hutan mempunyai iklim mikro yang berbeda dengan keadaan sekitarnya cahaya lebih sedikit, kelembaban sangat tinggi dan temperatur cukup rendah. Sehingga di dalam hutan hujan tropis disamping hidup berbagai jenis pohon juga dapat dijumpai jenis tumbuhan lain seperti tumbuhan epifit, tumbuhan liana, juga tumbuhan yang bersifat parasit dan saprofit.

Salah satu tumbuhan yang terdapat dalam hutan tropis Indonesia yaitu ditemui spesies kantong semar (Nepenthes spp.). Dari 82 spesies yang teridentifikasi di dunia 64 jenisnya ditemui di Indonesia diantaranya tersebar di pulau Jawa 2 spesies, Sulawesi 19 spesies, Sumatera 29 spesies, Papua 9 spesies, Maluku 4 spesies dan Kalimantan (Handoyo:2006:16).

Provinsi Sumatera Barat berada di garis khatulistiwa, sehingga tidak mengherankan tingginya keanekaragaman flora dan fauna didaerah ini. Berdasarkan data yang diperoleh dari Balai Konservasi Sumber Daya Alam (BKSDA) Sumatera Barat, Luas kawasan konservasi yang dikelola BKSDA Sumatera Barat adalah 247.282 ha, jumlah ini mencakup $10,38 \%$ dari luas hutan di Sumatera Barat (Jusmar dkk,2012:8).Salah satu tumbumbuhan yang terdapat dan dilindungi di Cagar Alam ini adalah spesies kantong semar (Nepenthes spp.).

Penelitian sebelumnya sudah pernah dilakukan oleh Pitra Akhriadi dan Hernawati dengan judul "a news spesies of Nepenthes (Nepentheceae) from Sumatra", dengan hasil penelitian ditemukan 31 spesies kantong semar (Nepenthes spp.) yang terdapat di Sumatera.

Cagar Alam Lembah Harau merupakan kawasan yang terletak di Kabupaten Lima Puluh 
Kota dengan luas 257, 24 ha. Kawasan Cagar Alam Lembah Harau disamping sebagai Cagar Alam juga berfungsi sebagai kawasan wisata alam dan banyak dikunjungi oleh wisatawan sehingga keberadaan berbagai spesies tumbuhan akan terancam kepunahannya termasuk kantong semar (Nepenthes spp.). Berdasarkan uraian diatas penelitimelakukan penelitian dengan judul "Studi Identifikasi spesies kantong semar (Nepenthes spp.)yang terdapatdi Kawasan Cagar Alam Lembah Harau Kabupaten Lima Puluh Kota, Sumatera Barat".

\section{METODOLOGI PENELITIAN}

Penelitian ini merupakan penelitian deskriptif dengan metode survey untuk mengetahui jenis jenis kantong semar (nepenthes $s p$ ), yang terdapat di kawasan Cagar Alam Lembah Harau Kabupaten Lima Puluh Kota yang dilaksanakan pada bulanOktober - November 2014 dan diidentifikasi di Laboratorium Biologi STKIP ABDI Pendidikan Payakumbuh.

\section{HASIL DAN PEMBAHASAN}

Berdasarkan hasil penelitian yang dilakukan di Kawasan Cagar Alam Lembah Harau Kabupaten Lima Puluh Kota Sumatera Barat dan telah diidentifikasi di laboratorium Biologi STKIP Abdi Pendidikan Payakumbuh, ditemukan 4 spesies kantong semar (Nepenthes spp.) yang terdapat di Kawasan Konservasi tersebut. Hal ini dapat dilihat pada Tabel berikut:

Tabel 1. Spesies Kantong Semar Di Kawasan Cagar Alam Lembah Harau Kabupaten Lima Puluh Kota

\begin{tabular}{|c|c|c|}
\hline No & Jenis (Spesies) & Nama daerah \\
\hline 1 & Nepenthes albomarginata & Aka sianguih \\
\hline 2 & Nepenthes eustachya Miq & $\begin{array}{c}\text { Katidiang } \\
\text { Baruak }\end{array}$ \\
\hline 3 & Nepenthes gracilis Korth & Kuran kuran \\
\hline 4 & $\begin{array}{c}\text { Nepenthes ampullaria } \\
\text { Jack }\end{array}$ & Godah \\
\hline
\end{tabular}

Adapun karakteristik morfologi nepenthes yangditemukanadalah sebagai berikut:

1. Nepenthes ampullaria Jack
Nepenthes ampullaria memiliki batang kecoklatan dengan batang memanjat (scandes). Bentuk daun ampullaria berupa daun bangun lanset (lanceolatus) dengan tepi daun rata (integer) permukaan daun licin (leavis) dengan daun bagian bawah berbulu dan warna daun hijau. Kantong ampullaria berbentuk tempayan yang muncul secara bergerombolan dari roset daun diatas permukaan tanah, ada juga yang ditemukan menggantung pada batang tegak. Warna kantongnya bewarna hijau dengan bibir kantong bewarna kecoklatan, dimana kantong atas lebih kecil dari kantong bawahnya.Ampullaria memiliki bunga berntuk tandan atau malai.

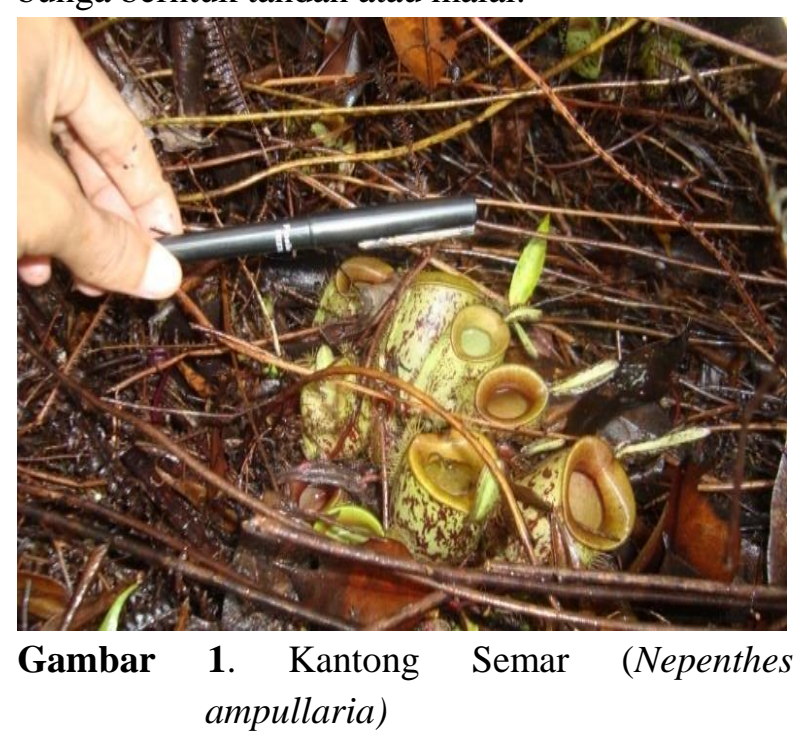

2. Nepenthes Gracilis Korth

Nepenthes Gracilis memiliki batang segitiga dengan batang bewarna hijau dan batang memanjat (scandes). Bentuk daun Gracilis berupa daun bangun lanset (lanceolatus) dengan tepi daun rata (integer) permukaan daun licin (leavis) dan warna daun hijau. Bentuk kantong gricilis oval dibagian bawah dan slinder dibagian atas. Kantong bawah dilengkapi dengan dua sayap berupa duri duri kecil yang sejajar keatas, dimana warna kantong Gracilis yang ditemukan adalah bewarna hijau dengan ukuran panjang kantong \pm $10 \mathrm{~cm}$ dan lebar $\pm 3.5 \mathrm{~cm}$. Gracilis memiliki bunga yang berbentuk tandan atau malai 


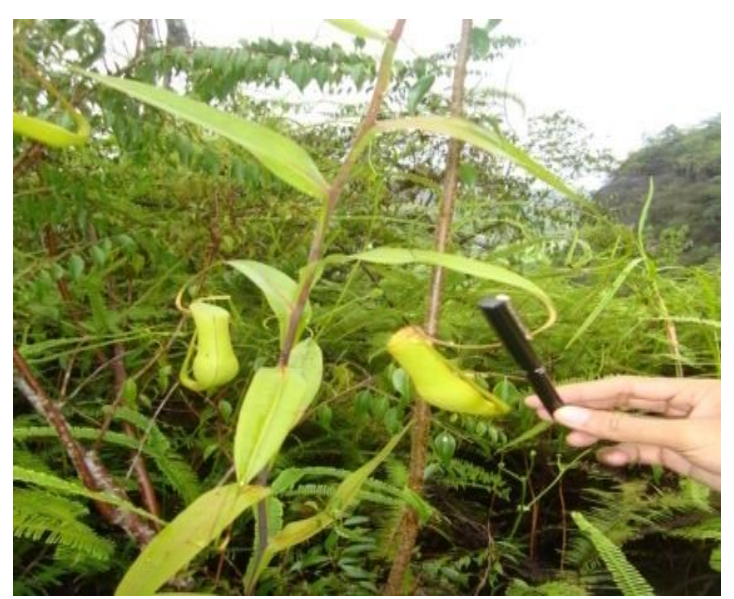

Gambar 2. Kantong Semar (Nepenthes gracilis)

\section{Nepenthes Eustachya Miq}

Eustachya memiliki batang bulat kehitaman dan batang memanjat (scandes). Bentuk daun Eustachya berupa daun bangun lanset (lanceolatus) dengan tepi daun rata (integer) permukaan daun licin (leavis), tulang daun bewarna merah dan daun bewarna hijau. Bentuk kantong Eustachya oval dibagian bawah dan slinder dibagian atas. Sayap kantong Eustachya tidak memiliki duri, serta salurnya bewarna merah. dimana warna kantong Eustachya yang ditemukan adalah bewarna hijau kemerahan dengan ukuran panjang kantong $\pm 7 \mathrm{~cm}$ dan lebar $\pm 2.5 \mathrm{~cm}$. Eustachya memiliki bunga yang berbentuk tandan atau malai

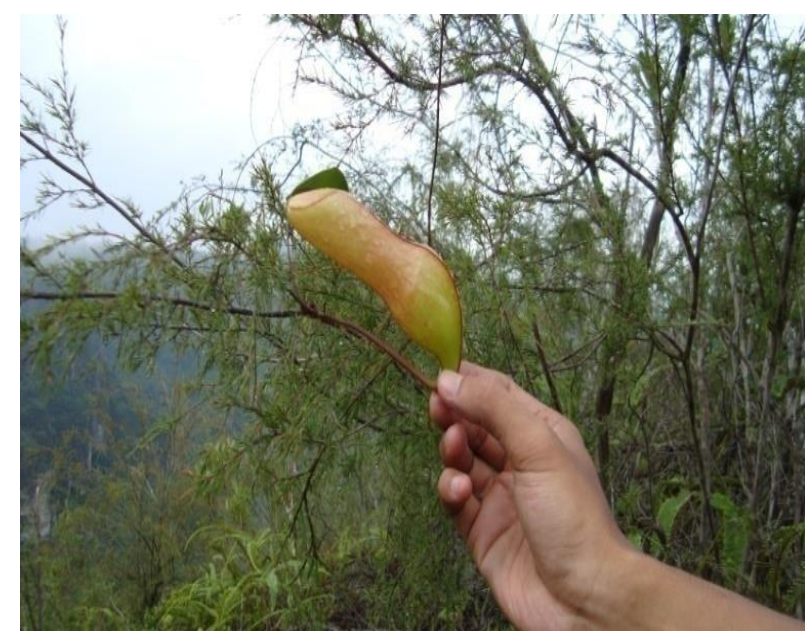

Gambar 3. Kantong semar (Nepenthes eustachya)

4. Nepenthes albomarginata T. Lobb ex Lindl albomarginata memiliki batang bulat kecoklatan dengan batang memanjat (scandes). Bentuk daun albomarginata berupa daun bangun lanset (lanceolatus) dengan tepi daun rata (integer) permukaan daun licin (leavis), dan daun bewarna hijau. . Sayap kantong albomarginata tidak memiliki duri, dan salurnya bewarna hijau. Warna kantong dari albomarginata yang ditemukan adalah hijau dengan ukuran panjang kantong $\pm 8 \mathrm{~cm}$ dan lebar $\pm 3 \mathrm{~cm}$. albomarginata memiliki bunga yang berbentuk tandan atau malai

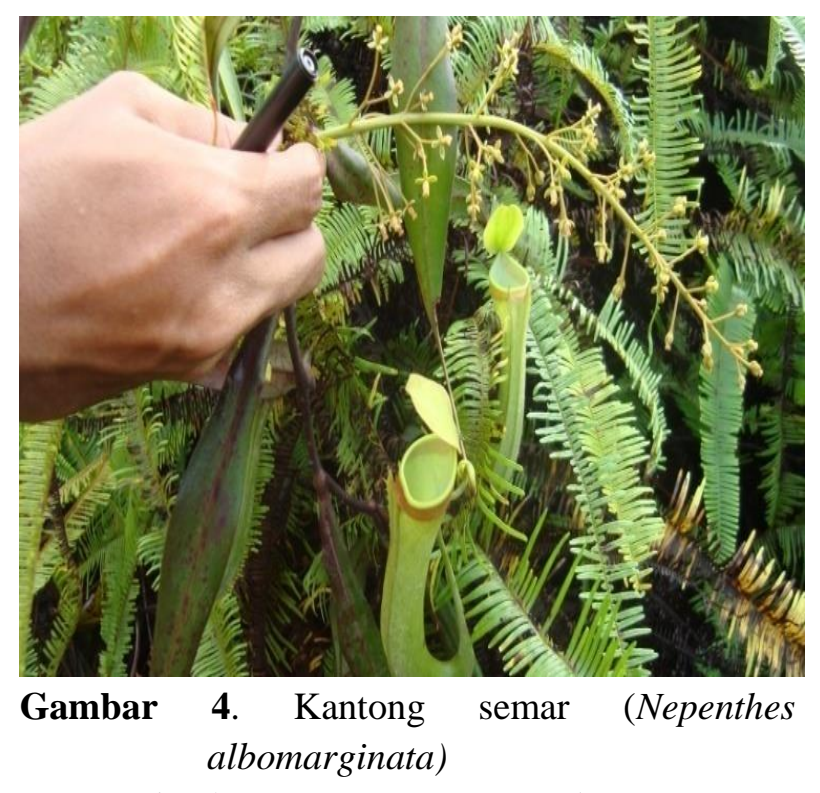

Spesies kantong semar (Nepenthes spp.) yang ditemukan pada penelitian ini tidak sama dengan yang dilaporkan dan dipublikasikan sesbelumnya. Penelitian yang dilakukan oleh Pitra Akhriadi dan Hernawati pada tahun 2004 menemukan 7 spesies kantong semar (Nepenthes spp.) yaitu Nepenthes eustachya, Nepenthes ampullaria, Nepenthes gracilis, Nepenthes albomarginata, Nepenthes longifolia, Nepenthes adnata, Nepenthes bongso, dengan pengambilan sampel di Kawasan Cagar Alam Lembah Harau dan Suaka Alam Air Putih. Pada penelitian ini ditemukan 4 spesies kantong semar (Nepenthes spp.) yang terdapat di Cagar Alam Lembah Harau, hal ini terjadi perbedaan karena peneliti hanya mengambil lokasi di Kawasan Cagar Alam Lembah Harau saja.

Jenis Nepenthes ampullaria dan N.eustachya masih banyak ditemukan tersebar di Kawasan Cagar Alam sedangkan untuk jenis $N$. albomarginata dan N.gracillishanya ditemukan pada lokasi tertentu.Jenis Nepenthes eustachya merupakan spesies yang endemic dan tumbuh baik di habitat aslinya yaitu tumbuh di tanah (terresterial) dengan batang memanjat (scandes) pada tumbuhan lain. 
Secara umum kantong semar (Nepenthes spp.) sudah dikenal oleh masyarakat disekitar kawasan konservasi yang dijadikan sebagai tempat penelitian, tidak mengherankan jika beberapa anggota masyarakat telah mengetahui jenis dan tempat hidup kantong semar di kawasan konservasi tersebut.

Masyarakat sekitar kawasan juga mengambil kantong semar yang ada untuk dipelihara sebagai tanaman hias serta dijual kepada para wisatawan yang datang sehingga dikhawatirkan populasinya akan berkurang dan terancam punah di Kawasan Cagar Alam Lembah Harau.

Kantong semar (Nepenthes spp.) dilindungi berdasarkan UU No. 5 tahun 1990 tentang konservasi sumber daya alam dan ekosistemnya dan peraturan presiden No.7 tahun 1999 tentang jenis tumbuhan dan satwa yang dilindungi. Oleh karena itu diperlukan pengawasan dan penyelamatan spesies ini oleh instansi terkait dan masyarakat baik melalui konservasi secara in-situ maupun ex-situ

Berdasarkan Gambar 7 didapat persamaan: y $=-263.92 \mathrm{x}-3.5455$. Adapun nilai energi aktivasi sebesar 2,19 kJ/mol. Muhammad dkk., (2012) telah mempelajari kajian kinetika pada reaksi oksidasi fenol menggunakan katalis Co/ANZ, energi aktivasi yang didapat sebesar 48, $\mathrm{kJ} / \mathrm{mol}$. Saputra dkk., (2013) juga mempelajari kajian kinetika pada reaksi degradasi fenol menggunakan persamaan Arrhenius, energi aktivasi yang diperoleh sebesar 11,4 kJ/mol.

\section{KESIMPULAN DAN SARAN \\ Kesimpulan}

Berdasarkan penelitian yang telah dilakukan didapatkan 4 spesies kantong semar (Nepenthes spp) yaitu $N$. albomarginata, $N$. eustachya, $N$. gracillis, $N$. ampullaria, yang tersebar di Kawasan Cagar Alam Lembah Harau

\section{Saran}

Diharapkan kepada instansi terkait terutama Balai Konservasi Sumber Daya Alam Sumatera
Barat untuk meningkatkan pengawasan terutama kepada masyarakat yang mengeksploitasi tumbuhan nepenthes $s p$ untuk diperdagangkan, serta memberikan penyuluhan mengenai jenisjenis flora maupun fauna yang dilindungi berdasarkan undang-undang Konservasi Sumber Daya Alam.

\section{DAFTAR PUSTAKA}

Atkins PW. 1999. Kimia Fisika. "Ed ke-2 Kartahadiprodjo Irma I, penerjemah ; Indarto Purnomo Wahyu, editor. Jakarta: Erlangga. Terjemahan dari: Physichal Chemistry.

Akhriadi, P, Hernawati and R. Tamin. 2004. A News spesie Nepenthes (Nepentheceae) From Sumatera. Reiwardtia 12 (2): 141144.

Departement Kehutanan. 2011. Cagar Alam Indonesia, http// Dep. Kehutanan, CagarCagar Alam, diakses 24 Februari 2014.

Fitriana, Rina. 2008. Mengenal Hutan. Bandung: Putra Setia

Giyarto. 2007. Mari bersahabat dengan Alam. Mataram: Ceraka Darma Aksara

Handoyo, Frankie. 2006. Petunjuk Praktis Perawatan Nepenthes. Jakarta: Agro Media Pustaka.

Jusmar, Aa dkk. 2012. Buku Informasi Balai Kawasan KSDA Sumatera Barat. Padang: Balai Konservasi Sumber Daya Alam Sumatera Barat.

Komunitas Dian Aksara. 2010. Mengenal Keanaka Ragaman Hayati. Bandung: PT Puri Pustaka.

Purwanto, Arie Wijayani. 2007. Nepenthes Kantong Semar nan Eksotis. Yogyakarta: Kanisius.

Undang-Undang Nomor 5 Tahun 1990 Tentang Konservasi Sumber Daya Alam Hayati dan Ekosistemnya. Departemen Kehutanan RI. 